

\title{
Manuel Paz y Montejo (1732 - ca 1807) Noticias biográficas de un olvidado pintor limeño
}

\author{
Omar Gonzalo Esquivel Ortiz \\ Universidad Nacional Mayor de San Marcos \\ omar.esquivel@unmsm.edu.pe
}

\begin{abstract}
Resumen
En el presente artículo se propone examinar y ofrecer nuevos alcances documentales sobre la identidad y trayectoria del pintor limeño Manuel Paz, artista cuya actividad poco atendida por los estudios especializados en arte virreinal de siglo XVIII, ha mantenido su actividad cerca del anonimato. Hemos recopilado los aportes biográficos y referencias más resaltantes sobre su obra, para revisarlas críticamente y establecer así una adecuada lectura hermenéutica de los documentos relativos al pintor, provenientes del Archivo Arzobispal de Lima y el Archivo General de la Nación.

Las reflexiones centrales de este artículo giran en torno a la identidad pública que construye este artista desde su temprana actividad, cuando con apenas 18 años realiza el lienzo de gran formato El bautismo de Cristo (1749), hasta sus últimas obras conocidas en el claustro conventual de La Merced de Lima (1786-1792). Cabe acotar, que hemos preferido respetar el nombre compuesto y original del pintor Manuel Paz, en lugar de Manuel de Paz, de acuerdo con las finalidades narrativas y demostrativas que plantea este artículo sobre la orfandad disimulada del pintor.
\end{abstract}

Palabras clave: pintura, virreinato, s. XVIII, San Lázaro, bautismo.

\begin{abstract}
The purpose of this article is to examine and offer new documentary scopes on the identity and career of Manuel Paz, Lima painter, an artist whose activity little attended by the specialized studies in the eighteenth century art, has kept his activity close to anonymity. We have compiled the most outstanding biographical contributions and references on his work, to review them critically and set forth an appropriate hermeneutic reading of the documents related to the painter, from the Archiepiscopal Archives of Lima and the General Archive of the Nation.

The central reflections of this article concentrates on the public identity that this artist builds from his early activity, when he was just 18 years old. At that time he made the large format canvas The Baptism of Christ (1749), until his last known works in the cloister convent of La Merced in Lima (17861792). It should be noted, that we have preferred to respect the compound and original name of the painter Manuel Paz, instead of Manuel de Paz, according to the narrative and demonstrative purposes that this article proposes on the concealed orphanhood of the painter.
\end{abstract}

Keywords: painting, viceroyalty, s. XVIII, San Lázaro, baptism. 


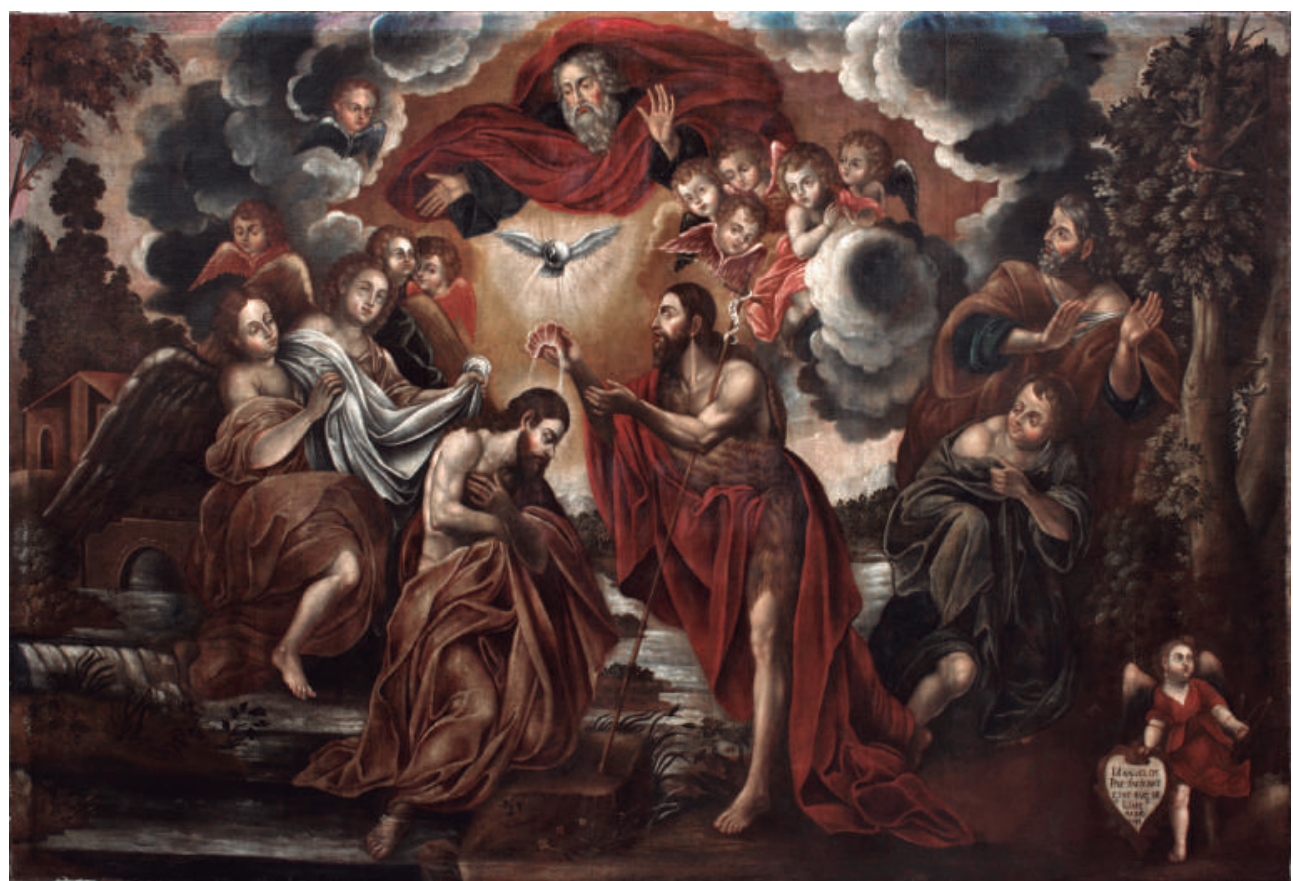

Fig.1. Manuel Paz. El bautismo de Cristo. Óleo sobre tela. 268 x 431 cm, 1749. Parroquia de San Lázaro, Rímac, Lima. Fotografía Omar Esquivel

Manuel de Paz es el nombre de un pintor limeño poco estudiado en el arte virreinal borbónico, pese a ser elegido como uno de los autores de los lienzos hagiobiográficos de San Pedro Nolasco para el claustro principal del convento de La Merced de Lima (1786-1792), por cierto, el último programa ambicioso de lienzos conventuales del virreinato; asimismo, es el autor de El bautismo de Cristo (1749), un olvidado lienzo de gran formato recientemente restaurado y conservado en la iglesia parroquial de San Lázaro ${ }^{1}$.

Las referencias biográficas de Manuel de Paz son, en general, escasas y poco exactas, más aún en lo referido a su trayectoria; sin embargo, ofrecen valiosos datos y un margen cronológico que han servido de guía para el hallazgo de nuevos documentos que detallan importantes aspectos sobre su vida y actividad, en especial el expediente judicial que abre Manuel Paz contra Marcos Ozinaga en 1782, conservado en el Archivo General de la Nación, el cual ha servido de fuente primaria para el ensayo analítico sobre su identidad social. Antes, merecen un repaso y una lectura crítica las mencionadas referencias que nos han antecedido.

En 2009, la investigadora Gabriela Lavarello señala a Manuel de Paz como "pintor mestizo”, sin referencia bibliográfica o de archivo que le respalde². En 2006, el historiador Luis Eduardo Wuffarden atribuye erróneamente a Manuel de Paz el lienzo San Pedro Nolasco suda sangre $^{3}$, pintado por Julián Jayo (ca. 1786), sin otra información adicional sobre su actividad.

1 Este lienzo fue analizado históricamente y restaurado en 2014, como parte del proyecto multidisciplinario Manuel Paz-1749: Recuperación de un lienzo votivo y fundacional del Rímac, dirigido por el expárroco de San Lázaro, Carlos Castillo Mattasoglio, y ejecutado por el restaurador Erman Guzmán Reyes y el historiador del arte Omar Esquivel Ortiz.

2 Lavarello, 2009, p. 309.

3 Wuffarden, 2006, pp. 124-127. 
En 1989 y 2003, tanto Bernales Ballesteros $^{4}$ como Paz-Soldán Bosa ${ }^{5}$ omiten las obras que Paz realiza en los claustros del Convento de La Merced de Lima.

La falta de exactitud y olvido de la obra de Paz podría deberse a una aparente dificultad de identificación y registro; no obstante, las cuatro obras de su autoría (dos de ellas firmadas) ubicadas en el Convento de La Merced, demuestran que estas referencias están basadas primordialmente sobre un meritorio trabajo de gabinete, dependiente de las fuentes escritas, pero de frágiles esfuerzos de observación directa sobre las piezas de arte. Esto explica la vigencia y repetitivo uso del único testimonio documentado de Manuel de Paz relacionado con su obra, ofrecido por el historiador Rubén Vargas Ugarte en 1968, más un aporte adicional del arquitecto Harth-Terré en 1963, los cuales citaremos más adelante.

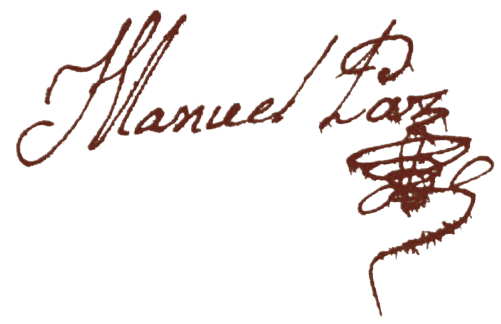

Fig.3. Firma Manuel Paz. En Real Audiencia, Causas Civiles, Leg. 233. Cuad. 2002. f. 14v (AGN). Digitalizado por Omar Esquivel

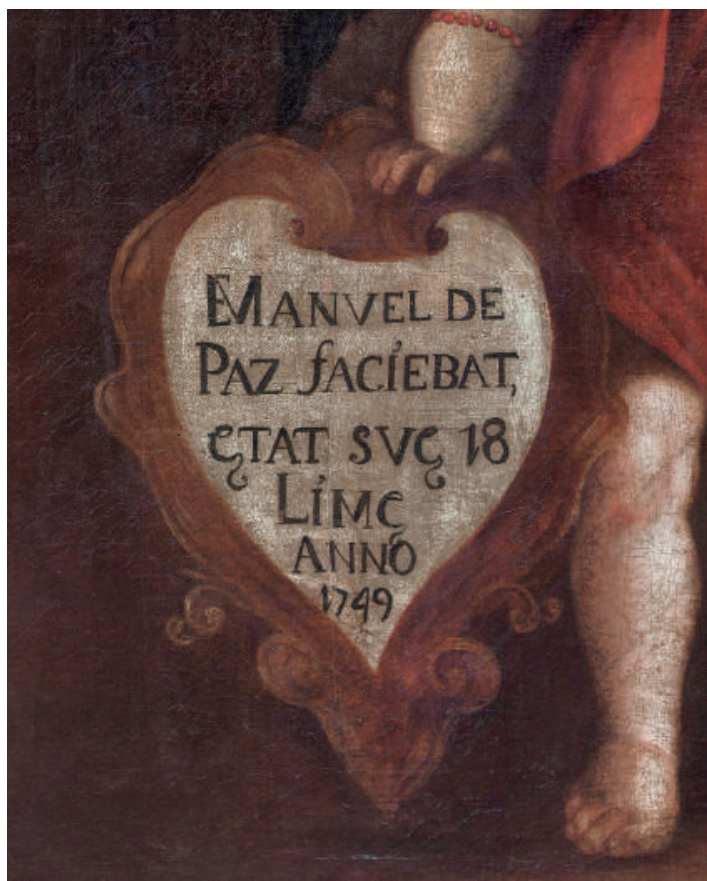

Fig. 2. Manuel Paz. El bautismo de Cristo (detalle de cartela). Óleo sobre tela. 268 x $431 \mathrm{~cm}$ (detalle 86.3 x $77.6 \mathrm{~cm}$.) 1749 . Parroquia de San Lázaro, Rímac, Lima. Fotografía Omar Esquivel

El bautismo de Cristo (1749) (Fig.1) es la quinta obra documentada de Manuel Paz custodiada en el templo de la Parroquia de San Lázaro, la misma que, se sabe, desde la década de 1930 ha permanecido expuesta ex situ a su contexto arquitectónico original ${ }^{6}$. En él, su autor firma en latín: EMANVEL DE PAZ fACÍEBAT (Fig.2).

El pintor establece una diferencia entre la preposición latina e y la preposición castiza de. Si la una es un ablativo de causa para referirse a sí mismo como el autor del cuadro y, además, aludir al origen hebreo de su nombre, la segunda otorga pertenencia genealógica a la familia Paz. Por lo tanto EManuel de Paz es una firma que hace públicamente legítima su autoría y su identidad genealógica. No obstante, en el citado auto judicial, el pintor firma como Manuel Paz (Fig.3), sin preposición alguna.

Si la obra es un objeto de culto público, ¿por qué modificar su identidad personal y familiar? El hábito de autodefinir la identidad antroponímica es una práctica común entre los

4 Bernales, 1989 , pp. 60 y 61.

5 Paz-Soldán Bosa, 2003, pp. 239-241.

6 Las dimensiones del lienzo antes de su restauración eran 268 x $431 \mathrm{~cm}$, incluido su marco tallado y dorado. Este ocupaba el muro de acceso a la capilla del Sagrado Corazón de Jesús, que invadía, además, el vitral de medio punto de la puerta de acceso. Consideramos que su lugar pudo estar relacionado con el baptisterio de dicho templo. 
ciudadanos limeños del periodo dieciochesco, como respuesta al interés de legitimar su raigambre genealógica a una clase estamentaria de mayor estatus y privilegios ${ }^{7}$. Sin embargo, esta explicación es aún tangencial; por ello, recurrimos a los registros eclesiásticos.

El 21 de febrero de 1749, en la Iglesia de la Vice Parroquia del Corazón de Jesús (también llamada de Los Huérfanos ${ }^{8}$ ), doña Mónica Marín y don Pascual de Jáuregui dan consentimiento al matrimonio de su hija Silvestra con " $D$ ". Man'. de Paz... español, Nat ${ }^{\text {al }}$. desta Ciu" ${ }^{\mathrm{d}}$. hijo de Thomasa Montejo, / y de Padre no conocido"9.

El nombre de Mónica Marín, suegra del pintor, de cuyo fallecimiento se da noticia en el citado expediente de 1782: " $D^{a}$. Mónica Marín mi Suegra difunta"10 es una prueba fehaciente de la identidad de Manuel Paz, el pintor, novio de Silvestra de Jáuregui, pero aquí cabe precisar algunas observaciones. El registro de padre no conocido en el acta de matrimonio delata la ruptura del pintor con su línea paterna, además de su condición de huérfano e hijo ilegítimo, razón por la cual no hereda el apellido Montejo de la madre y le sustituye por Paz.

De acuerdo con las Siete Partidas, uno de los cuerpos de leyes más empleado por la Corona en el virreinato peruano, la orfandad de padre de un niño puede ser cubierta por la madre, solo bajo la condición de ser "muger de buena fama" y "mantoviere biudez, e non casare"11; a ello, se agrega la alta probabilidad de haber encargado el tutelaje de Manuel a algún pariente o cercano maestro dedicado a la pintura ${ }^{12}$, taller en el cual se instruye tempranamente, hasta que a sus 18 años consigue la prematura madurez para pintar El bautismo de Cristo (1749).

Sea nombre compuesto o apellido sustituto, el pintor construye un autoconcepto a partir de la ostentación pública de su firma en el lienzo El bautismo de Cristo, el cual alcanza un valor legítimo cuando transmite el apellido Paz a su única hija, Manuela Paz ${ }^{13}$. Se desconoce la fecha de nacimiento del pintor, debido a su biografía indocumentada. No obstante, los datos declarados en su matrimonio y su edad descrita en el lienzo, son claves para definir el siguiente perfil de búsqueda entre las actas de niños bautizados de Lima. Se describe:

- Nombre: Manuel

- Nacido entre 1730 y 1732

- Hijo natural de Thomasa Montejo y huérfano de padre

- Limeño y descendiente de español

De acuerdo con estas premisas, solo un acta bautismal guarda correspondencia cronológica con dicho perfil ${ }^{14}$. Transcribimos la siguiente acta declarada en el libro de españoles de la Parroquia de San Lázaro:

Lunes nueve de Junio de Setecientos y treinta y dos / yo el Br. D. Franco. Xavier de Cordova de lisencia / parrochi, exorsise puse oleo y chrisma por haver/le vaptisado

7 Tales son los casos de los pintores Julián Dávila Taulichumbi Saba Mango Capac Inga y de José Gil de Carbajal y Castro. Esquivel, 2015, pp. 29-36, 42-46.

8 Ubicada hoy en Jr. Apurímac 386, Cercado de Lima.

9 Libro de actas matrimoniales de El Sagrario n. ${ }^{\circ}$ 9, fol. 158 (AAL).

10 Real Audiencia, Causas Civiles, leg. 233, cuad. 2002, f. 6 (AGN).

11 Según Ley XIX. Bernuy, 1758, p. 206.

12 Borges, 2016, p. 137-142.

13 De acuerdo con el poder recíproco para testar con su esposo, el palmesano don Amador Gaya, registrado en 1807, doña Manuela Paz afirma ser: "Hija lexitima de Dn. Manuel de Paz, y de Doña / Silvestra Jauregui mis Padres Difuntos". Protocolos notariales 398, fol. 127v (AGN).

14 Basado en la búsqueda de las actas de bautismo de las parroquias de Lima (excepto la de Santiago del Cercado): San Marcelo, San Lázaro, El Sagrario, San Sebastián y Santa Ana, más la viceparroquia de Huérfanos, comprendidas entre los años 1707 y 1762. 
en caso de Nesesidad el P Presenta/do frai Pedro De Lara, Religioso Dominico a / Manuel de edad de quatro meses hijo natural / de Da. Thomasa de la Crus; fue su Pdrino el $\mathrm{P}^{\mathrm{e}}$. / $\mathrm{M}^{\circ}$. frai Agustín de Zuñiga thestigos el Pe. frai / Domingo Medrano y Gerónimo Casasola / $\mathrm{B}^{\mathrm{r}}$. D. Franco. $\mathrm{X}^{\mathrm{r}}$. de Cordova ${ }^{15}$.

Si bien el cambio de apellidos es una práctica habitual entre ciudadanos españoles y mestizos, no en los nombres, por ello consideramos que el distintivo doña y el nombre Thomasa son probablemente los mismos de doña Thomasa Montejo, mientras "de la Cruz", con mayor probabilidad un nombre compuesto, al igual que su hijo Manuel Paz.

Su inexacta fecha de nacimiento en 1732 y los que refiere tener el pintor en la firma de El bautismo de Cristo: "ȨTAT SVȨ 18 / LIMȨ / ANNO / 1749", colocaría en el campo de la hipótesis nuestro hallazgo, pese a ser la única partida bautismal compatible, sin embargo, si se considera que: 1 . Su nacimiento ocurre en los últimos días de enero de 1732, 2. El pintado de la cartela de El bautismo de Cristo, con el año 1749, se realiza al final del proceso de elaboración del lienzo, y 3. La elaboración de El bautismo de Cristo sucede en el tránsito de cumplir 18 años en los últimos días de 1749, el autor podría haber pintado "1749" como testimonio del año del encargo y de sus 18 años apenas cumplidos en febrero de 1750 .

En cualquier caso, el distintivo matrimonial don califica a Manuel Paz como ciudadano, a su vez que permite identificar los 51 años que posee en 1782 durante el pleito contra Ozinaga, fecha en la que alcanza una aparente estabilidad en el oficio de pintor, el cual le permite sostener una vivienda en la calle de los Estudios ${ }^{16} \mathrm{y}$, además, arrendar una tienda en la esquina de Nuñez ${ }^{17}$, en donde incorpora a Gregorio Villaroel de 20 años, en calidad de colaborador de su taller. Tiene, además, en Isidro Tallar, un frecuente cliente con quien también establece un vínculo amistoso, y un lazo familiar con María Encamación Valverde, quien habita en su casa luego de fallecer doña Mónica Marín, circunstancia que permite considerar un segundo lazo matrimonial o conyugal con María tras el posible fallecimiento o separación con doña Silvestra de Jáuregui, a quien no se le menciona en ninguna parte del expediente judicial.

Entre 1749 y 1782 no hay registros sobre su actividad, pese a corresponder a una etapa de importante vitalidad y madurez del pintor, anterior a las cuatro obras que realiza para el convento de Nuestra Señora de La Merced de Lima, fechados en 1786:

- Pedro Nolasco es presentado en el templo (sin fecha ni firma)

- Pedro Nolasco ante el cardenal Pedro Duacense (firmado y fechado en 1786)

- Pedro Nolasco ante los herejes albigenses (sin fecha ni firma)

- El rapto de Pedro Nolasco por la Santísima Trinidad (firmado sin fecha)

De los 31 lienzos que componen la serie, Manuel Paz se ocupa de estos cuatro, de similares dimensiones a El bautismo de Cristo, los cuales representan la primera etapa de la vida pública del santo fundador. Vargas Ugarte, en 1968, afirma que dos lienzos de todo el conjunto fueron realizados "en nuestros tiempos [por] un pintor, Pazmiño, de Guayaquil (...)"18. Su aparente error en la lectura de las firmas explica el por qué se ha identificado tardíamente su participación en la serie ${ }^{19}$. Citamos la firma del segundo cuadro: "Paz.Mefecit año de

15 Libro de bautismo de españoles de San Lázaro n. ${ }^{\circ}$ 8, fol. 169 (AAL).

16 Real Audiencia, Causas Civiles, leg. 233, cuad. 2002, f. 8 (AGN). La “Casa de Vicuña” se situaba en la cuadra 4 de jirón Ucayali, en el Cercado de Lima.

17 Ibíd., fol. 8v. Situada en la actual cuadra 2 de jirón Miró Quesada en el Cercado de Lima.

18 Lo referido a los cuadros de La Merced solo son incluidos en la biografía del pintor Julián Jayo. Vargas Ugarte, 1968, p. 415.

19 Durante su restauración en 2005. 


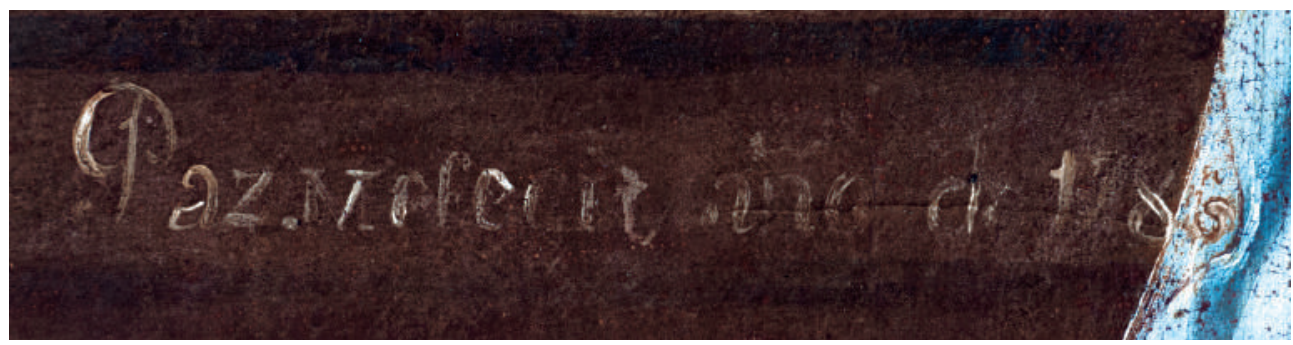

Fig.4. Manuel Paz. La bendición del cardenal Pedro Duacense al niño Pedro Nolasco y la entrega de sus vestidos a los niños pobres (detalle de firma). Óleo sobre tela. 260 × $306 \mathrm{~cm}$, detalle 6

1786" (Fig.4). Paz me hizo, año de 1786. El pintor reitera su linaje paterno, aunque con menor índole demostrativa que en su primera obra.

Durante estos años, luego de fallecer los pintores Cristóbal de Aguilar (¿?-1769) ${ }^{20}$ y Cristóbal Lozano (1705?-1776) ${ }^{21}$, los encargos más resaltantes en la pintura limeña de tipo secular y religioso son asumidos por Pedro José Díaz, criollo limeño (¿?-1810? 22, y Julián Jayo, cacique indígena (1737?-1821)23, quienes también elaboran obras para el Convento de La Merced entre 1786 y $1792^{24}$, y para la Iglesia Recoleta de Religiosos Dominicos de Lima en $1808^{25}$. Pedro Díaz, por otra parte, deriva su labor como tasador de obras de arte, al igual que Manuel Paz. Según Vargas Ugarte: “En 1788 fue llamado juntamente con Pedro Díaz para examinar un gran lienzo que había sido enviado del Cuzco y se consideraba de mérito (...)"26.

Díaz, quien se encontraba en Chincha, es remplazado por Felipe Cáceres. Junto a Paz tasan el lienzo la "Trinidad y San Gregorio... [de] 7 varas de largo y 4 de ancho" en 120 pesos debido a su "deplorable estado" de conservación, pese a su factura "italiana muy fina" 27.

Dedicado a cobrador de cofradías ${ }^{28}$, pintor y tasador de obras de arte, Manuel Paz perfila una activa y destacada participación en el medio comercial de la pintura. A esta búsqueda también corresponde su necesidad de instalar vivienda y taller en el centro de comercio y producción manufacturera de la ciudad, estatus que también condiciona su filiación a la parroquia de El Sagrario, a través de la viceparroquia de Huérfanos, en donde contrae matrimonio y donde, según Eguiguren y Harth-Terré, habita en 1792 en un nuevo domicilio situado en la calle del Noviciado (hoy cuadra 8 de jr. Azángaro, en el Cercado de Lima), frente al mismo templo, junto a sus hijos Jorge, Toribio y Ventura, "a quienes enseño su arte y le ayudaban en sus tareas" 29 , además de su única hija Manuela Paz, quien en 1807 refiere de Manuel Paz y Silvestra de Jáuregui: "mis Padres Difuntos"30; siendo este el último rastro biográfico conocido del pintor.

20 Estabridis, 2004, pp. 29-40.

21 Estabridis, 2001, pp. 299, 315.

22 Pintor de quien se tiene escasas referencias documentadas.

23 Esquivel, 2015, pp. 29-36.

24 De Pedro Díaz la imagen de Santa Cecilia, firmada sin fecha, y de Julián Jayo, 21 de los 31 lienzos que componen la serie de San Pedro Nolasco en el claustro principal.

25 Díaz se encarga de la imagen principal de la Virgen de Chiquinquirá, y Jayo de dos lienzos sobre la vida de la Virgen María. Parada, 1808, pp. 24, 34.

26 Vargas Ugarte, 1968, pp. 440 y 441.

27 Ibid.

28 Según atestigua el propio pintor en sus descargos contra Ozinaga en el expediente de 1782.

29 Harth-Terré, 1963, p. 201. El autor no cita ninguna fuente del presente dato, no obstante, es dado a conocer por primera vez en la Calles de Lima, de Eguiguren, 1945, p. 225.

30 Protocolos notariales 398, fol. 127v (AGN). 


\section{Archivos consultados}

Archivo General de la Nación (AGN)

Archivo Arzobispal de Lima (AAL)

\section{Referencias bibliográficas}

Bernales Ballesteros, J. (1989). "La pintura en Lima durante el Virreinato". En Pintura del Virreinato del Perú. Lima, Banco de Crédito del Perú, 31-108 pp.

Bernuy, C. (1758). Las siete partidas del sabio rey D. Alfonso el Nono, copiadas de la edición de Salamanca del año de 1555, que publicó el señor Gregorio López, Partida VI. Valencia: Por Joseph Thomás Lucas, en la Plaza de las Comedias.

Borges, A. de Souza, Marina y Luisa Vetter Parodi (2016). Artesanos huérfanos y desamparados: Perú siglos XVI y XVII. En: Diálogo Andino. Revista de Historia, Geografía y Cultura Andina, n. ${ }^{\circ}$ 49, pp. 137-142. Recuperado de https://dx.doi. org/10.4067/S0719-26812016000100016

Eguiguren, L. A. (1945). Las Calles de Lima: miscelánea, propietarios y vecinos, los dueños de carruajes y calesas (siglo XVIII), costumbres antiguas, las provincias y departamentos a través de sus nombres y calles en la capital, el fundador de la imprenta en el Perú. Lima: s.n.

Esquivel Ortiz, O. (2015). Un retrato de Bolívar. Estudio introductorio a la obra de Pablo Roxas. Lima: Seminario de Historia Rural Andina, Universidad Nacional Mayor de San Marcos.

Estabridis, R. (2001). "Cristóbal Lozano, paradigma de la pintura limeña del siglo XVIII". En Barroco Iberoamericano: territorio, arte, espacio y sociedad, vol. 1. Sevilla, editorial Giralda, pp. 345-364.

Estabridis, R. (2004). "Cristóbal de Aguilar Casaverde, retratista limeño del siglo XVIII". En: Illapa $\mathrm{n} .{ }^{\circ} 1$, Instituto de Investigaciones Museológicas y Artísticas de la Universidad Ricardo Palma. Lima: Universidad Ricardo Palma, pp. 29-40.
Harth-Terré, E. y A. Márquez Abanto (1963). “Las Bellas Artes en el Virreinato. Pinturas y pintores en Lima virreinal". En: Revista del Archivo Nacional del Perú, t. XXVII, entregas I y II. Lima: Librería e imprenta Gil, pp. 104-218.

Lavarello, G. (2009). Artistas plásticos en el Perú: siglos XVI-XVII-XVIII-XIX-XX. Lima: Pacasmayo.

Parada y Pinzón, V. (1808). Cuenta y razón de la entrada, destino y existencia de las limosnas recogidas y ofrecidas a Maria Santisima baxo la advocación de la Virgen del Rosario de Chiquinquira que actualmente se venera en la iglesia de Santa María Magdalena de religiosos dominicos de esta ciudad de Lima. Lima: Imprenta de la Real Casa de Niños Expósitos.

Paz-Soldán Boza, M. F. (2003). "Panorama de la pintura virreinal peruana: escuela limeña". En: Campos, Norma (ed.). Memoria del I Encuentro Internacional "Barroco andino". La Paz: Artes Gráficas Sagitario, pp. 230-244.

Vargas Ugarte, R. (1968). Ensayo de un diccionario de artífices de la América Meridional. Burgos: Imprenta de Aldecoa.

Wuffarden, L. E. (2006). "Avatares del 'bello ideal'. Modernismo clasicista versus tradiciones barrocas en Lima, 1750-1825”. En: Mujica, Ramón (ed.). Visión y símbolos: del virreinato criollo a la República Peruana. Lima: Banco de Crédito del Perú, pp. 113-160.

Recibido el 2 de agosto del 2018

Aceptado el 28 de agosto del 2018 